\title{
ROLE OF OPTICAL COHERENCE TOMOGRAPHY IN DIABETIC MACULOPATHY IN NON- PROLIFERATIVE DIABETIC RETINOPATHY AND ITS MANAGEMENT
}

\author{
Preeta Nair A. K1, Ranisujatha M. $A^{2}$
}

${ }_{1}^{1}$ Postgraduate Resident, Department of Ophthalmology, Dr. B. R. Ambedkar Medical College, Bengaluru, Karnataka, India. ${ }^{2}$ Professor and HOD, Department of Ophthalmology, Dr. B. R. Ambedkar Medical College, Bengaluru, Karnataka, India.

\section{ABSTRACT}

\section{BACKGROUND}

Diabetic retinopathy and diabetic macular oedema are leading causes of blindness throughout the world and cause significant visual morbidity. Ocular imaging has played a significant role in management of diabetic eye disease.

Aim- To study the role of OCT in management of diabetic maculopathy in Non-Proliferative Diabetic Retinopathy.

\section{MATERIALS AND METHODS}

A descriptive study was conducted over a period of 18 months from June 2016 to November 2017 at Dr. B. R. Ambedkar Medical College and Hospital, Bengaluru. A total of 100 eyes of 50 patients were taken into the study. Informed consent was obtained from all the patients considered for the study. A detailed history, ocular examination, best corrected visual acuity, intraocular pressure with GAT, visual fields and fundus examination using indirect ophthalmoscope, +90D lens and OCT was done.

\section{RESULTS}

Among the patients who received anti-VEGF treatment best corrected visual acuity improved in $38 \%$ of cases, while $15 \%$ of cases showed no improvement.

\section{CONCLUSION}

Incidence of diabetic maculopathy is common after 50 years with diabetes of longer duration. Disease affects both eyes asymmetrically. OCT is an important diagnostic tool to detect maculopathy and helps in deciding further management based on the type of maculopathy. Early treatment with double frequency Nd-YAG green laser of $532 \mathrm{~nm}$ can stabilise the visual acuity and prevent further visual loss. Diabetic maculopathy is the commonest cause of visual loss in patients with Diabetic Retinopathy. Regular followup and repeated OCT examination is mandatory to detect the involvement of macula at an earlier stage.

\section{KEY WORDS}

OCT: Optical Coherence Tomography; GAT: Goldmann's Applanation Tonometer; Nd-YAG: Neodymium Yttrium Aluminium Garnet. HOW TO CITE THIS ARTICLE: Nair PAK, Ranisujatha MA. Role of optical coherence tomography in diabetic maculopathy in nonproliferative diabetic retinopathy and its management. J. Evolution Med. Dent. Sci. 2018;7(21):2634-2637, DOI: $10.14260 /$ jemds/2018/591

\section{BACKGROUND}

Diabetic retinopathy and diabetic macular oedema are leading causes of blindness throughout the world and cause significant visual morbidity. Ocular imaging has played a significant role in management of diabetic eye disease. Retinal oedema threatening or involving the fovea often results in vision loss. It is an important consequence of abnormal retinal vascular permeability in diabetic retinopathy. The diagnosis of DME is made when retinal thickening is observed with slit-lamp biomicroscopy or on OCT. Observations include the location of retinal thickening relative to the foveal centre; presence and location of exudates; and presence of cystoid macular oedema. Fluorescein angiography is useful in demonstrating the breakdown of the blood-retina barrier by showing retinal capillary leakage. However, examination with OCT or slit-lamp

'Financial or Other Competing Interest': None.

Submission 12-04-2018, Peer Review 05-05-2018,

Acceptance 11-05-2018, Published 21-05-2018.

Corresponding Author:

Dr. Ranisujatha M. A,

Professor and HOD,

Department of Ophthalmology,

Dr. B. R. Ambedkar Medical College,

Bengaluru, Karnataka.

E-mail: drranisujathama@gmail.com

DOI: $10.14260 /$ jemds $/ 2018 / 591$

\section{(c) (i) $\odot$}

biomicroscopy is done. Fluorescein angiogram is performed for confirming the microaneurysms, which appear as a group of punctate foci of hyperfluorescence. Diffuse macular oedema demonstrating diffuse thickening of the retina with glistening surface. Fluorescein angiogram confirming the diffuse intraretinal leakage. Leakage shown on the angiogram may occur in the absence of macular retinal thickening and is thus not considered macular oedema.

\section{Aim of the Study}

To study the patients with diabetic maculopathy in NPDR coming to Dr. B. R. Ambedkar Medical College OPD and IPD. Specific Objectives-

a. To study various types of Diabetic Macular Oedema using OCT.

b. To evaluate the visual outcome after treating with antiVEGFs.

\section{MATERIALS AND METHODS}

A descriptive study was conducted over a period of 18 months from June 2016 to November 2017 at Dr. B. R. Ambedkar Medical College and Hospital, Bangalore.

A total of 100 eyes of 50 patients were taken into the study. Informed consent was obtained from all the patients. 
Patients were enrolled in the Study if they satisfied the following Criteria-

\section{Inclusion Criteria}

1. Both sex.

2. Age between 40 and 70 years.

3. Patients with type 2 Diabetes Mellitus.

4. Duration: $5-20$ years.

\section{Exclusion Criteria}

1. Patients with opaque media.

2. Patients with proliferative diabetic retinopathy.

3. Neovascular glaucoma.

4. Vascular occlusions.

5. Juvenile diabetes mellitus.

Detailed history, ocular examination, best corrected visual acuity, intraocular pressure with GAT, visual fields, fundus examination using indirect ophthalmoscopy and fundus fluorescein angiography, OCT was done.

\section{RESULTS}

\section{Age of Onset}

In our study, the age group predominantly affected was $51-60$ years (34\%) followed by 61 - 70 years (24\%) and 41 - 50 years range $(20 \%) .54 \%$ of cases were aged between $41-60$ yrs. $^{1}$ (Figure 1).

\begin{tabular}{|c|c|c|c|}
\hline $\begin{array}{c}\text { Sl. } \\
\text { No. }\end{array}$ & $\begin{array}{c}\text { Age Groups } \\
\text { in Years }\end{array}$ & $\begin{array}{c}\text { No. of } \\
\text { Patients }\end{array}$ & $\begin{array}{c}\text { Percentage } \\
\text { (\%) }\end{array}$ \\
\hline 1 & $41-50$ & 10 & 20 \\
\hline 2 & $51-60$ & 17 & 34 \\
\hline 3 & $61-70$ & 12 & 24 \\
\hline 4 & $71-80$ & 3 & 6 \\
\hline \multicolumn{3}{|c|}{ Table 1 } \\
\hline
\end{tabular}

2. DME Incidence with Advancing Severity of Diabetic Retinopathy

$56 \%$ of patients with severe NPDR had macular oedema as compared to $36 \%$ with moderate NPDR and $8 \%$ with mild NPDR (Figure 4).

\begin{tabular}{|c|c|c|}
\hline NPDR & $\begin{array}{c}\text { No. of Patients with } \\
\text { DME }\end{array}$ & $\begin{array}{c}\text { \% Patients with } \\
\text { DME }\end{array}$ \\
\hline Mild & 4 & 8 \\
\hline Moderate & 18 & 36 \\
\hline Severe & 28 & 56 \\
\hline \multicolumn{2}{|c|}{ Table 2 } \\
\hline
\end{tabular}

3. Moderate and Severe Visual Loss in Anti-VEGFs treated patients with CSME

\begin{tabular}{|c|c|c|}
\hline Visual Loss & No. of Cases & \% \\
\hline Moderate & 13 & 37.14 \\
\hline Severe & 1 & 2.85 \\
\hline Table 3. 37.14\% had Moderate Visual Loss and 2.85\% had \\
Severe Visual Loss \\
\hline
\end{tabular}

4. Retinal Thickening after 1 Year Follow-Up with OCT Among treated patients retinal thickening persisted only in $35 \%$, whereas $63 \%$ of untreated patients showed retinal thickening (Figure 5).

\begin{tabular}{|c|c|c|c|}
\hline $\begin{array}{c}\text { No. of } \\
\text { Patients }\end{array}$ & & $\begin{array}{c}\text { Retinal } \\
\text { Thickening }\end{array}$ & \% Persistence \\
\hline Treated & 36 & 12 & 35 \\
\hline Untreated & 14 & 9 & 63 \\
\hline \multicolumn{3}{|c|}{ Table 4 } \\
\hline
\end{tabular}

\section{Visual Acuity on Presentation}

$30 \%$ patients had $6 / 24-6 / 60$ visual acuity on presentation and $7 \%$ had $<3 / 60 .^{2}$

\begin{tabular}{|c|c|c|}
\hline $\begin{array}{c}\text { Best Corrected Visual Acuity } \\
\text { on Presentation }\end{array}$ & No. of Cases & $\%$ \\
\hline $6 / 6-6 / 12$ & 10 & 10 \\
\hline $6 / 12-6 / 24$ & 27 & 27 \\
\hline $6 / 24-6 / 60$ & 30 & 30 \\
\hline $6 / 60-3 / 60$ & 24 & 24 \\
\hline$<3 / 60$ & 7 & 7 \\
\hline \multicolumn{2}{|c|}{ Table 5 } \\
\hline
\end{tabular}

Hence, majority of our patients presented in the visual acuity range of 6/24 - 6/60 (Figure 2).

\section{Visual Outcome after treatment with anti-VEGFs ${ }^{3}$}

\begin{tabular}{|c|c|c|}
\hline $\begin{array}{c}\text { Best Corrected Visual Acuity } \\
\text { after Anti-VEGF }\end{array}$ & No. of Cases & $\mathbf{\%}$ \\
\hline $\begin{array}{c}\text { Number of patients who gained } 10 \\
\text { or more letters }\end{array}$ & 38 & 38 \\
\hline No improvement & 15 & 15 \\
\hline \multicolumn{2}{|c|}{ Table 6 } \\
\hline \multicolumn{2}{|c|}{} \\
\hline
\end{tabular}

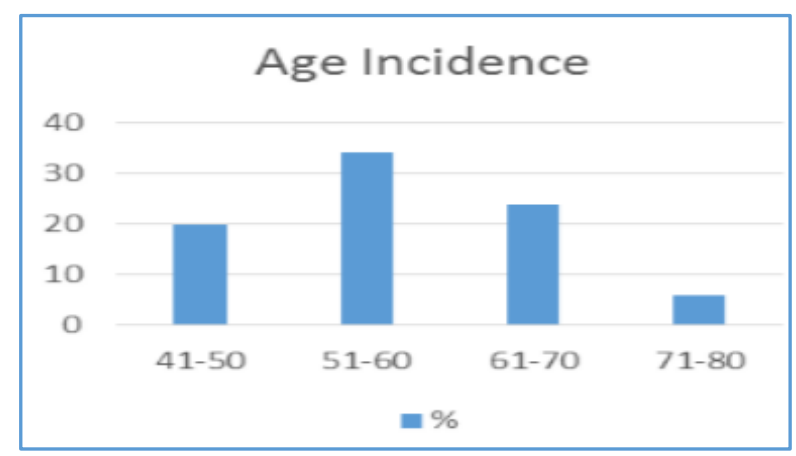

Figure 1

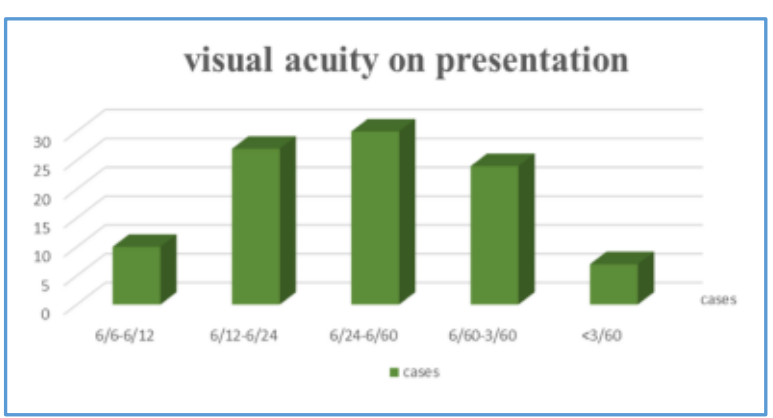

Figure 2 


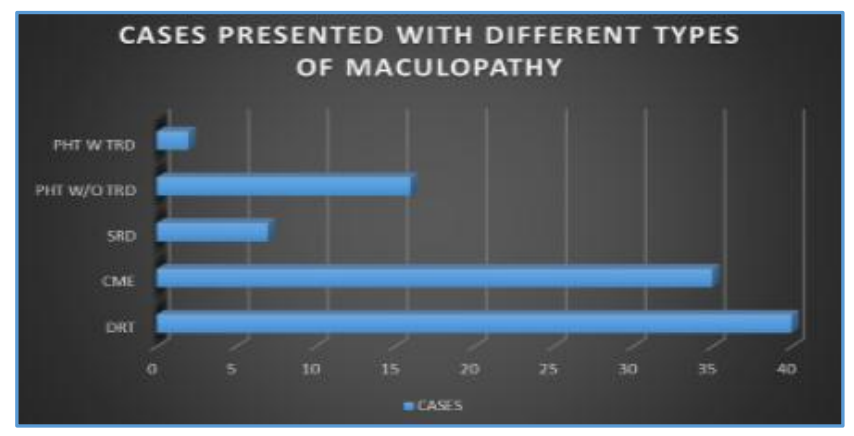

Figure 3

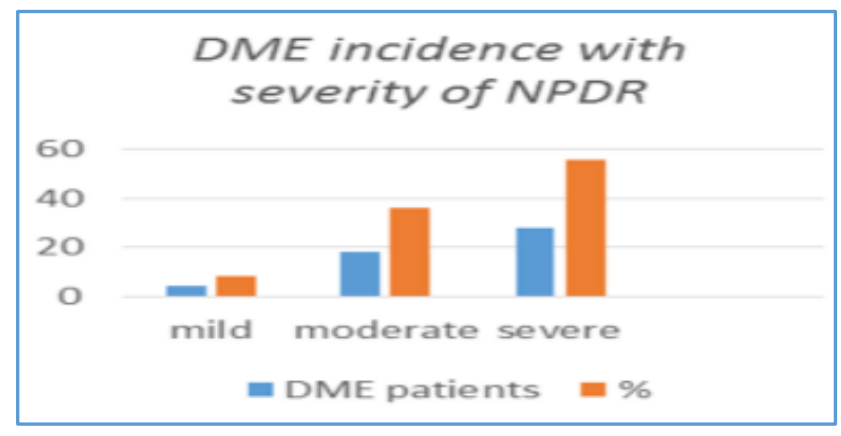

Figure 4

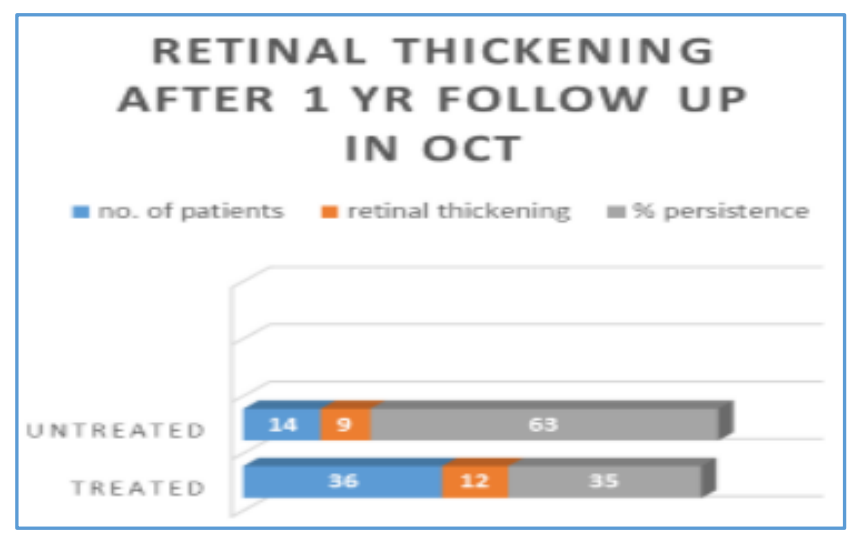

Figure 5

\section{DISCUSSION}

Diabetes Mellitus is a condition in which the blood glucose levels are elevated. It mainly affects small vessels and involvement of retina is common. ${ }^{4}$ According to ETDRS, diabetic retinopathy is divided into Mild, Moderate, Severe NPDR and Proliferative Retinopathy. ${ }^{5}$ Diabetic Maculopathy is one of the components of DR which has direct effect on vision, more in NPDR patients. Prevalence of DME in DR patients is 29\%.6 DME is defined as oedema/ hard exudates present within $500 \mu \mathrm{m}$ of the foveal centre or oedema of > 1DD of the foveal centre. ${ }^{7}$ This study was carried out to learn the role of OCT in early detection of diabetic maculopathy and its management.

Optical Coherence Tomography (OCT) is a non-invasive, non-contact transpupillary imaging modality. It utilises light to image tissue using low coherence interferometry. OCT produces cross-sectional images of the macula allowing objective evaluation of macular thickness and evaluation of the vitreomacular interface. However, it must be noted that there is poor correlation between macular thickness and visual acuity. Several OCT patterns of morphological macular changes associated with DME have been described. These include diffuse retinal thickening, cystoid macular oedema, posterior hyaloid traction, serous retinal detachment and tractional retinal detachment. ${ }^{8}$ These patterns are not exclusive of each other and may co-exist with one another. OCT is an essential tool in the current management of this condition. Anti-VEGF therapy plays an increasing role in the treatment of DME. 9

In our study the age group affected predominantly are between 41 - 60 years, which correlates with the Wisconsin Epidemiological Study of Diabetic Retinopathy (Klein et al. Arch. 1986) that shows diabetic retinopathy more common in the elderly population aged 45 to 64 years.

According to Wisconsin Epidemiological Study of Diabetic Retinopathy, macular oedema was more prevalent in severe NPDR than others. In our study $56 \%$ of patients with severe NPDR had macular oedema, $36 \%$ with moderate NPDR and $8 \%$ with mild NPDR. The current study shows that there is a moderate visual loss among 33.3\% untreated patients and severe visual loss among $6.6 \%$ patients untreated. Among the patients treated with anti-VEGFs, $37 \%$ had moderate visual loss and $3 \%$ had severe visual loss which correlates with the ETDRS that the treatment with anti-VEGFs are effective in preventing visual acuity loss. ${ }^{10}$

In this study, OCT shows retinal thickening in 35\% of treated patients and $63 \%$ of untreated patients after a 1-year follow-up. ${ }^{11}$

In the current study, $30 \%$ patients had visual acuity of $6 / 24-6 / 60$ on presentation and $7 \%$ had $<3 / 60$. Hence, majority of our patients presented in the visual acuity range of 6/24 - 6/60, which correlates with the Becker et al study. Patients with diffuse maculopathy had visual acuity in the range of $6 / 60-3 / 60$ on presentation. Ischaemic maculopathy patients had visual acuity of $6 / 24$ or less on presentation. Most patients with focal type had good visual acuity initially. After treatment with anti-VEGF, $38 \%$ of patients had at least 10 letter improvement of best corrected visual acuity.

\section{CONCLUSION}

Diabetic Maculopathy is the commonest cause of visual loss in patients with Diabetic Retinopathy. Regular follow-up and examination is necessary to detect the involvement of macula at an earlier stage. 12

Incidence of diabetic maculopathy is common after 50 years with diabetes of longer duration. ${ }^{13}$ Disease affects both eyes asymmetrically. OCT is an important diagnostic tool to detect maculopathy. Early treatment with anti-VEGFs improves the visual acuity and prevent further visual loss. ${ }^{14}$ Repeated injection of anti-VEGFs depends upon the severity of the diabetic macular oedema. ${ }^{15}$

\section{REFERENCES}

[1] Klein R, Klein BE, Moss BE, et al. The Wisconsin epidemiologic study of diabetic retinopathy. IV. Diabetic macular edema. Arch Ophthalmol 1984;91(12):1464-74.

[2] Early Treatment Diabetic Retinopathy Study Research Group. Treatment techniques and clinical guidelines for photocoagulation of diabetic macular edema. Early Treatment Diabetic Retinopathy Study Report Number 2. Ophthalmol 1987;94(7):761-74.

[3] Davis MD. Proliferative diabetic retinopathy. In Ryan SJ, edr. Retina. Vol. 2. $4^{\text {th }}$ edn. St Louis, MO: Mosby 2006: p. 1285-322. 
[4] Frank RN. Etiologic mechanisms in diabetic retinopathy. Chap - 66. In: Ryan SJ, Hinton DR, Schachat AP, et al. eds. Retina. Vol. 2. $4^{\text {th }}$ edn. St. Louis, MO: Mosby 2006: p. 1241-70.

[5] Aiello LM, Cavallerano JD, Aiello LP, et al. Diabetic retinopathy. In: Guyer DR, Yannuzi LA, Chang S, et al. eds. Retina vitreous macula. Vol. 2. 1999: p. 316-44.

[6] Ahmad L, Khan TH, Bundela RK, et al. Prevalence of DME in association with severity of diabetic retinopathy. JMSCR 2017;5(2):17847-52.

[7] Benson OE, Tasman W, Duane TD. Diabetes mellitus and the eye. Chap - 30. In: Duane's Clinical ophthalmology. Vol. 3. Philadelphia: JB Lippincott Co., 1990: p. 1-29.

[8] Kim BY, Smith SD, Kaiser PK. Optical coherence tomographic patterns of diabetic macular edema. Am J Ophthalmol 2006;142(3):405-12.

[9] Federman JL, Gouras P, Schubert H, et al. Systemic diseases. In: Podos SM, Yanoff M, eds. Retina and vitreous: Textbook of ophthalmology. $9^{\text {th }}$ edn. London: Elsevier Health Sciences 1994: p. 7-24.

[10] Mitchell P, Wong TY, Diabetic Macular Edema Treatment Guideline Working Group. Management paradigms for diabetic macular edema. Am J Ophthalmol 2014;157(3):505-13.e1-8.
[11] Panazzo G, Gusson E, Parolini B, et al. Role of OCT in diagnosis and follow up of diabetic macular edema. Seminars in Ophthalmology 2003;18(2):74-81.

[12] Adler AI, Stratton IM, Neil HA, et al. Association of systolic blood pressure with macrovascular and microvascular complications of type 2 diabetes (UKPDS 36): prospective observational study. BMJ 2000;321(7258):412-9.

[13] HDS HIDSG. Hypertension in Diabetes study (HDS): I. Prevalence of hypertension in newly presenting type 2 diabetic patients and the association with risk factors for cardiovascular and diabetic complications. J Hypertens 1993;11(3):309-17.

[14] Akduman L, Olk RJ. The early treatment for diabetic retinopathy study. In: Kertes $\mathrm{C}$, edr. Clinical trials in Ophthalmology: a summary and practice guide. Baltimore: Williams and Wilkins 1998: p. 15-36.

[15] Quillen DA, Gardner TW, Blankenship GW. The diabetic retinopathy study. In: Kertes C, edr. Clinical trials in ophthalmology: a summary and practice guide. 1998: $\mathrm{p}$. $1-14$. 